\title{
Dose effect of alpha-linolenic acid on lipid metabolism in the hamster
}

\author{
Anne Morise ${ }^{\mathrm{a}}$, Jacques Mourot ${ }^{\mathrm{b}}$, Michel RiotTot $^{\mathrm{a}}$, Pierre WEILL $^{\mathrm{c}}$, \\ Evelyne FÉNART ${ }^{\mathrm{d}}$, Dominique HERMIER ${ }^{\mathrm{a}, \mathrm{e} *}$ \\ a Laboratoire de Physiologie de la Nutrition, Bât. 447, Université Paris-Sud, 91405 Orsay Cedex, France \\ b INRA, SENAH, Saint-Gilles, 35590 L'Hermitage, France \\ c Valorex, La Messayais, 35210 Combourtillé, France \\ d ONIDOL, 12 avenue George V, 75008 Paris, France \\ e Present address: UMR Physiologie de la Nutrition et du Comportement Alimentaire, INA-PG, \\ 16 rue Claude Bernard, 75231 Paris Cedex 05, France
}

(Received 22 July 2004; accepted 31 January 2005)

\begin{abstract}
In order to meet dietary requirements, the consumption of $\alpha$-linolenic acid (ALA, 18:3 n-3) must be promoted. However, its effects on triglyceride (TG) and cholesterol metabolism are still controversial, and may be dose-dependent. The effects of increasing dietary ALA intakes $(1 \%, 10 \%$, $20 \%$ and $40 \%$ of total FA) were investigated in male hamsters. ALA replaced oleic acid while linoleic and saturated FA were kept constant. Triglyceridemia decreased by $45 \%$ in response to $10 \%$ dietary ALA and was not affected by higher intakes. It was associated with lower hepatic total activities of acetyl-CoA-carboxylase (up to $-29 \%$ ) and malic enzyme (up to $-42 \%$ ), which were negatively correlated to ALA intake $\left(r^{2}=0.33\right.$ and $r^{2}=0.38$, respectively). Adipose tissue lipogenesis was 26 fold lower than in the liver and was not affected by dietary treatment. Substitution of $10 \%$ ALA for oleic acid increased cholesterolemia by $15 \%$ but, as in TG, higher ALA intakes did not amplify the response. The highest ALA intake $(40 \%)$ dramatically modified the hepatobiliary metabolism of sterols: cholesterol content fell by $45 \%$ in the liver and increased by $28 \%$ in the faeces. Besides, faecal bile acids decreased by $61 \%$, and contained more hydrophobic and less secondary bile acids. Thus, replacing $10 \%$ oleic acid by ALA is sufficient to exert a beneficial hypotriglyceridemic effect, which may be counteracted by the slight increase in cholesterolemia. Higher intakes did not modify these parameters, but a very high dose resulted in adverse effects on sterol metabolism.
\end{abstract}

$\alpha$-linolenic acid / oleic acid / lipogenesis / cholesterol / triglyceride / bile acid / hamster

Abbreviations: ACC: Acetyl CoA Carboxylase, ALA: $\alpha$-linolenic acid, BA: bile acid, CE: cholesteryl esters, CVD: cardiovascular disease, DHA: docosahexaenoic acid, EAT: epididymal adipose tissue, EPA: eicosapentaenoic acid, FAS: fatty acid synthase, FC: free cholesterol, G6PDH: glucose 6 phosphate dehydrogenase, ME: malic enzyme, PL: phospholipids, PUFA: polyunsaturated fatty acid, TC: total cholesterol, TG: triglyceride.

\footnotetext{
* Corresponding author: hermier@inapg.inra.fr
} 


\section{INTRODUCTION}

$\mathrm{N}-3$ polyunsaturated fatty acids (PUFA) either in the form of the essential precursor $\alpha$-linolenic acid (ALA, 18:3n-3) or its long chain derivatives eicosapentaenoic and docosahexanoic acids (EPA, 20:5 n-3 and DHA, 22:6n-3) [1] are known to exert protective effects against various pathologies, and especially cardiovascular diseases (CVD) [2-4]. Despite these beneficial effects, the dietary intake of n-3 PUFA is largely insufficient in many Western countries [5-7], and must be promoted. This can be achieved through a higher consumption of ALA which is easily available in some vegetable oils such as linseed, perilla, and to a lesser extent, walnut, rapeseed and soybean oils. Their acceptance is largely better than that of fish oils, and they represent a major source of n-3 PUFA in people who do not usually eat fish, which are the main source of EPA and DHA. However, the rationale of replacing n-3 long-chain PUFA (LCPUFA) by their precursor ALA is still under debate, especially concerning their respective efficiency and mechanisms of action [8]. Indeed, ALA and its long chain derivatives exhibit similar positive effects on etiologic factors of CVD such as hemostasis, thrombogenesis [9], and blood pressure [10]. In contrast, the effects of ALA on lipid metabolism are still controversial. Whereas most human studies show that, when replacing saturated fatty acids (SFA), ALA exhibits the same hypocholesterolemic effect as linoleic acid (LA) [11-14], its effect on triglyceridemia is still unclear. Indeed, some human studies exhibited no effects of dietary ALA (4-5\% total energy intake) on triglyceridemia [12, 15], or a slight increase (with intake of ALA reaching 1.8\% total energy intake) [16], whereas supplementation with $60 \mathrm{~mL}$ linseed oil per day (12\% total energy intake) decreased plasma TG concentration [17]. Moreover, a recent epidemiological survey highlighted an inverse relation between ALA consumption and plasma TG concentration (after adjustment for other dietary parameters) [18]. Studies in the rat suggested that mechanisms involved in the decreased triglyceridemia could rely, as with n-3 LC-PUFA, on gene regulation resulting in a decreased activity [19] and expression [20] of key lipogenic enzymes and sometimes on a rise in mitochondrial oxidation [21], this latter effect being controversial [19]. Some of these discrepancies could originate from the different doses of dietary ALA used in human studies, which varied between 1.8 and $12 \%$ of total energy intake. Besides, the specific effects of ALA on lipid metabolism interact with those of other dietary fatty acids, especially through the ratio of LA to ALA and that of SFA to PUFA. To our knowledge, only two human studies specifically dedicated to the dose effect of dietary ALA were performed, but their dietary conditions were less controlled than in animals $[22,23]$ and the qualitative variations in dietary lipid composition between studies make the comparison very difficult. As for animal studies on the doseeffect of dietary ALA, they are scarce; indeed, seminal studies by Holman et al. used PUFA deficient rats and low ALA intakes [24, 25]. Those by Kabir et al. used a broader range of ALA intake but LA content was also variable [26].

The purpose of this study was therefore to investigate the dose-response effects of dietary ALA on some key points of TG and cholesterol metabolism. We analysed the lipid composition of plasma, liver and bile, the activities of some lipogenic enzymes in the liver and epididymal adipose tissue (EAT) and the excretion of faecal sterols. The dose response effects of dietary ALA were investigated over a broad range of ALA intake, while keeping those of LA and SFA constant. The rationale behind this was to provide ALA by substitution of a physiologically neutral FA (oleic acid), instead of FA known for their metabolic effects. We chose the hamster as a validated model for assessing the effects of dietary fats on lipid metabolism [27-29]. Moreover, our previous study in this model demonstrated that PUFA conversion, bioavailability and storage in the hamster is highly 
responsive to the dietary dose of ALA [30]. Indeed, ALA transport in plasma cholesteryl esters (CE) and storage in adipose tissue, as well as conversion into EPA (as assessed by the EPA proportion in phospholipids (PL) from plasma, red blood cells and the heart) were proportional to the dietary ALA dose, and did not tend to a plateau. This linear relationship between dietary ALA bioavailability of some n-3 PUFA was a prerequisite for investigating whether the influence of dietary ALA on lipid metabolism was dose-dependent. Special attention was paid to the possible adverse effects of the highest ALA intakes.

\section{MATERIALS AND METHODS}

\subsection{Experimental procedure}

\subsubsection{Animals}

Twenty-four male golden Syrian hamsters were obtained from Janvier (Centre d'élevage Janvier, Le Genest-St Isle, France) at 4 weeks of age. They were housed in colony cages with wood litter (6/cage) in a controlled environment $\left(22^{\circ} \mathrm{C}, 14 / 10 \mathrm{~h}\right.$ light: dark cycle) and received distilled water and a ground commercial diet ad libitum (containing, by weight, $72.0 \%$ cereals, $17.8 \%$ soy meal, $6.0 \%$ fish meal, $4.2 \%$ vitamin and mineral mixture and providing $19.3 \%$ proteins and $5.1 \%$ lipids, $52.4 \%$ of which were LA and 5.3\% ALA) (UAR 113, Villemoisson, France). At 8 weeks of age, the hamsters were housed in colony cages with wire floors, weighed weekly and fed experimental diets.

\subsubsection{Diets}

The four experimental diets consisted (in weight) of $84.4 \%$ of the above commercial ground pellets, $3 \%$ water, $0.03 \%$ cholesterol (5-cholesten-3B-ol, Sigma, St. Louis, USA) and $12.5 \%$ vegetable oil mixture. The calculated composition (in weight) of the
4 diets was $16.3 \%$ protein, $52.6 \%$ carbohydrate, $16.6 \%$ lipid, $11.8 \%$ water and $4.6 \%$ minerals. Lipids provided about $1 / 3(35.3 \%)$ of the total energy intake. The vegetable oil mixture consisted of linseed oil $(53.6 \%$ ALA, $15.7 \%$ LA, $20 \%$ oleic acid and $10 \%$ SFA) (Valorex, Javené, France) and high oleic sunflower oil (0.1\% ALA, $14.6 \%$ LA, $74.9 \%$ oleic acid and $10 \%$ SFA) added in different proportions in order to increase ALA concentration and to keep the levels of LA and SFA constant. As a consequence, ALA and oleic acid (18:1 n-9) varied in opposite proportions. The calculated proportions of linseed oil and high oleic sunflower oil were the following: 0/100, 22/78, $47 / 53$ and $97 / 3$, providing theoretically 1 , $10,20,40 \%$ ALA (as \% of total FA) in the L1, L10, L20 and L40 diets, respectively. The contribution of ALA to the total energy intake varied from less than $1 \%$ (L1 diet) to $14.6 \%$ (L40 diet). The composition of the experimental diets was determined as described below and is shown in Table I. All diets provided similar amounts of lipids, cholesterol and phytosterols (which interfere with dietary cholesterol absorption), so that the only lipid variable was the fatty acid composition.

\subsubsection{Experimental design}

After 5 weeks on the experimental diets, the hamsters were housed in individual cages with wire floors in order to measure their dietary consumption and to collect the faeces during the 7th week. In order to assess the body weight gain during the last week, the hamsters were weighed after an overnight fast $(18 \mathrm{~h})$ at the end of the 6th week. At 15 weeks of age, having been on the experimental diets for 7 weeks, all hamsters were fasted overnight, then weighed and anesthetised by intramuscular injection of Zoletil 50 (Virbac, Carros, France) at a dose of $4 \mathrm{mg} \cdot 100 \mathrm{~g}^{-1}$ of body weight. Blood was taken by intracardiac puncture, using a heparinised syringe (10 units heparin $\cdot \mathrm{mL}^{-1}$ blood). Plasma was separated from the blood by centrifugation for $20 \mathrm{~min}$ at $4{ }^{\circ} \mathrm{C}$ 
Table I. Lipid composition of the experimental diets.

\begin{tabular}{|c|c|c|c|c|c|}
\hline & & L1 & L10 & L20 & L40 \\
\hline Total lipids & $\mathrm{g} \cdot 100 \mathrm{~g}$ diet $^{-1}$ & 15.7 & 16.0 & 14.9 & 15.6 \\
\hline Cholesterol & & 0.072 & 0.075 & 0.075 & 0.072 \\
\hline Phytosterols & & 0.068 & 0.075 & 0.073 & 0.076 \\
\hline Fatty Acids & $\%$ of total fatty acids & & & & \\
\hline 4:0 & & 0.52 & 0.09 & 0.12 & 0.08 \\
\hline $8: 0$ & & 0.06 & 0.07 & 0.08 & 0.04 \\
\hline 10:0 & & 0.04 & 0.02 & 0.02 & 0.02 \\
\hline 14:0 & & 0.11 & 0.12 & 0.13 & 0.15 \\
\hline 16:0 & & 6.49 & 6.60 & 7.36 & 7.84 \\
\hline 18:0 & & 3.74 & 3.50 & 3.83 & 3.52 \\
\hline $18: 1 n-9$ & & 63.74 & 55.47 & 43.95 & 21.79 \\
\hline $18: 2 n-6$ & & 23.65 & 23.48 & 24.28 & 24.55 \\
\hline $18: 3 n-3$ & & 1.05 & 9.95 & 19.50 & 41.30 \\
\hline $20: 1 n-9$ & & 0.33 & 0.36 & 0.34 & 0.39 \\
\hline $20: 5 n-3$ & & 0.04 & 0.10 & 0.11 & 0.12 \\
\hline $22: 6 n-3$ & & 0.21 & 0.23 & 0.30 & 0.25 \\
\hline$\Sigma$ SSFA & $\%$ of total fatty acids & 10.96 & 10.40 & 11.54 & 11.65 \\
\hline$\Sigma$ MUFA & & 64.07 & 55.83 & 44.29 & 22.18 \\
\hline$\Sigma$ PUFA & & 24.95 & 33.77 & 44.19 & 66.22 \\
\hline$\Sigma \mathrm{n}-6$ & & 23.65 & 23.48 & 24.28 & 24.55 \\
\hline$\Sigma \mathrm{n}-3$ & & 1.30 & 10.29 & 19.91 & 41.67 \\
\hline $18: 2 n-6 / 18: 3 n-3$ & & 22.52 & 2.36 & 1.25 & 0.59 \\
\hline $18: 3 n-3$ & $\%$ of total energy intake & 0.4 & 3.6 & 6.7 & 14.6 \\
\hline
\end{tabular}

The diets consisted of commercial ground pellets and mixture of vegetable oils: linseed oil and high oleic sunflower oil. $\Sigma$ SFA, sum of saturated fatty acids; $\Sigma$ MUFA, sum of monounsaturated fatty acids; $\Sigma$ PUFA, sum of polyunsaturated fatty acids; $\Sigma \mathrm{n}-6$, sum of n-6 fatty acids; $\Sigma \mathrm{n}-3$, sum of n-3 fatty acids.

and $1700 \mathrm{~g}$ then stored at $-20{ }^{\circ} \mathrm{C}$. After blood sampling, the abdominal cavity was opened surgically and bile was taken from the gallbladder and stored at $-20^{\circ} \mathrm{C}$. The liver was then carefully removed and weighed, a $1 \mathrm{~g}$ sample was immediately frozen in liquid nitrogen for the measurement of lipogenic enzyme activity, and another sample of about $0.5 \mathrm{~g}$ was stored at $-20{ }^{\circ} \mathrm{C}$ for further analysis of lipid composition. Epididymal adipose tissue (EAT) was removed, weighed and frozen in liquid nitrogen for further measurement of lipogenic enzyme activity. The hamsters were then killed by section of the jugular vein. The present work was carried out in agreement with the
French legislation on animal experimentation and with the autorisation of the French Ministry of Agriculture (Animal Health and Protection Directorate).

\subsection{Analyses}

\subsubsection{Dietary lipids}

Lipids were extracted according to the Folch method [31], dried under $\mathrm{N}_{2}$ and weighed. They were then either trans-methylated for FA analyses, or saponified for further sterol extraction. Trans-methylation was performed with $\mathrm{BF}_{3}$ in methanol (14\%) according to the method of Morisson and 
Smith [32]. Fatty acid methyl esters (FAME) were analysed by GLC with a chromatograph (Fisons 8000, Thermo products, Les Ulis, France) under the conditions described by Morise et al. [30]. Saponification of lipids was performed at $85^{\circ} \mathrm{C}$ with ammonia $(2 \mathrm{~N})$ in ethanol, then neutral sterols (containing cholesterol and phytosterols) were extracted with petroleum ether, using ${ }^{14} \mathrm{C}$ cholesterol (Perkin Elmer Life Sciences, Boston, USA, $45 \mathrm{mCi} \cdot \mathrm{mmol}^{-1}$ ) as a marker. Neutral sterols were silylated with Derivasil (Chrompack, Middelburg, the Netherlands) and separated by GLC, using a HRGC 4100 apparatus (Carlo-Erba, Milan, Italy) equipped with a standard fused silica WCOT capillary column cross-linked with OV1 (25 m length, film thickness $0.2 \mu \mathrm{m})$ (Spiral, Dijon, France). Cholestane-5 $\alpha$ (Sigma, Saint-Quentin-Fallavier, France) was added to the samples as a standard for cholesterol and phytosterol quantification.

\subsubsection{Faecal sterols}

Neutral and acid (containing biliary acids) sterols were extracted from the faeces following a method described by Boehler et al. [33]. Briefly, after hydration of the faeces, lipids were extracted and hydrolysed in basic conditions. Neutral sterols were extracted with petroleum ether, while acid sterols remained in the aqueous phase. ${ }^{3} \mathrm{H}$ cholesterol (NEN, Life Science Product, Boston, USA, $46.5 \mathrm{Ci} \cdot \mathrm{mmol}^{-1}$ ) and ${ }^{14} \mathrm{C}$ taurocholate (Dupont NEN, Boston, USA, $46.4 \mathrm{mCi} \cdot \mathrm{mmol}^{-1}$ ) were used as markers of extraction. Free bile acids were methylated with diazomethane, silylated with Derivasil and analysed on a Carlo-Erba HRGC 5160 gas chromatograph equipped with the same column as described above for dietary neutral sterols. The oven temperature was $230{ }^{\circ} \mathrm{C}$, and the flow rate of the carrier gas (hydrogen) was $2 \mathrm{~mL} \cdot \mathrm{min}^{-1}$. Cholestane-5 $\alpha$ was added to the samples as a standard for the quantification of bile acids (BA), that are primary BA which include endogen bile acids, chenodesoxycholic acid (CDCA) and cholic acid (CA), and secondary BA which are microbial derivatives from the primary ones and consist essentially in lithocholic (LCA) and desoxycholic acids (DCA). In the calculations, we also considered two families of BA: those belonging to the CA biosynthesis pathway, i.e. the CA and the DCA, and those belonging to the CDCA pathway; i.e., the CDCA, 7-oxolithocholic acid and LCA.

Neutral sterols were separated by GLC, as described for the diet. Cholesterol excretion represents the weight of cholesterol and its bacterial derivatives excreted in the faeces per day, and corrected by $\beta$-sitostanol that is not absorbed and was considered as the internal standard.

\subsubsection{Plasma, bile and liver}

The following components were quantified in the plasma: TG, total cholesterol (TC), PL by colorimetric enzymatic methods using the kits provided by Bio-Merieux (Marcy-l'Étoile, France) [34-36]. The analyses were performed with an automatic analyser (Abbott-VP, Rungis, France). Free cholesterol (FC) was determined manually using a procedure adapted from Richmond [34]. The concentration of CE was calculated with the formula: $\mathrm{CE}=(\mathrm{TC}-\mathrm{FC}) \times$ 1.67. Non apo-B lipoproteins, i.e. HDL, were isolated from plasma by precipitation of apoB-lipoproteins with antibodies, using a kit provided by Biomerieux (Marcyl'Étoile, France) according to the method of Burstein et al. [37]. HDL-TC and -PL were then quantified in the supernatant as previously described above for plasma. Non HDL-TC, i.e. VLDL- and LDL-TC, was calculated with the formula: non HDL$\mathrm{TC}=$ plasma $\mathrm{TC}-\mathrm{HDL}-\mathrm{TC}$.

Bile PL and TC were assayed with the same procedures after bile dilution in distilled water (1/10). Bile acids (BA) were determined by an enzymatic manual procedure after bile dilution in distilled water $(1 / 20)$ [38]. The lithogenic index was calculated according to the Hofmann method [39], using the TC, PL and BA concentrations. 
Table II. Growth and body parameters.

\begin{tabular}{lccccc}
\hline & Unit & L1 & L10 & L20 & L40 \\
\hline Final body weight & $\mathrm{g}$ & $120 \pm 2^{\mathrm{a}}$ & $115 \pm 1^{\mathrm{ab}}$ & $110 \pm 2^{\mathrm{b}}$ & $110 \pm 3^{\mathrm{b}}$ \\
Weight gain & ${\mathrm{g} \cdot \text { day }^{-1}}^{\mathrm{b}}$ & $0.67 \pm 0.60^{\mathrm{ab}}$ & $1.89 \pm 0.74^{\mathrm{a}}$ & $-0.44 \pm 1.06^{\mathrm{b}}$ & $1.58 \pm 0.44^{\mathrm{ab}}$ \\
Dietary intake & $\mathrm{g} \cdot \mathrm{day}^{-1}$ & $6.05 \pm 0.11^{\mathrm{ab}}$ & $6.29 \pm 0.19^{\mathrm{a}}$ & $5.77 \pm 0.25^{\mathrm{b}}$ & $6.02 \pm 0.11^{\mathrm{ab}}$ \\
Liver weight & $\mathrm{g}$ & $4.10 \pm 0.09$ & $3.94 \pm 0.05$ & $3.84 \pm 0.08$ & $3.90 \pm 0.14$ \\
& \% body weight & $3.53 \pm 0.06$ & $3.49 \pm 0.04$ & $3.44 \pm 0.07$ & $3.40 \pm 0.04$ \\
EAT weight & $\mathrm{g}$ & $2.51 \pm 0.22$ & $2.31 \pm 0.13$ & $2.40 \pm 0.05$ & $2.62 \pm 0.24$ \\
& \% body weight & $2.26 \pm 0.15$ & $2.10 \pm 0.10$ & $2.09 \pm 0.06$ & $2.18 \pm 0.19$ \\
\hline
\end{tabular}

The results are mean \pm standard error of the mean of 6 hamsters in each group. Values with different superscripts are considered significantly different at $P<0.05$. The L1, L10, L20 and L40 diets contained respectively $1,10,20$ and $41 \%$ (total fatty acids) of ALA or $0.4,3.6,6.7$ and $14.6 \%$ of total energy intake. EAT, epididymal adipose tissue.

Hepatic lipids were determined as above for plasma lipids after extraction in isopropanol from a $150 \mathrm{mg}$ liver sample as described by Loison et al. [40]. The pellet was kept and solved in $\mathrm{NaOH} 1 \mathrm{M}$ for further determination of hepatic proteins (PR) determined according to Lowry et al. [41] using bovine serum albumin as the standard.

\subsubsection{Lipogenic enzymes}

The activities of the lipogenic enzymes were determined in the liver and epididymal adipose tissues as described by Mourot et al. [42]. Briefly, the tissues were homogenised in $0.25 \mathrm{M}$ sucrose and centrifuged at $40000 \mathrm{~g}$ for $40 \mathrm{~min}$. The supernatant cytosolic fractions were analysed for malic enzyme (ME, EC 1.1.1.40) and glucose-6-phosphate dehydrogenase (G6PDH, EC 1.1.1.49) using modifications [43] of the methods of Fitch et al. [44] and Hsu and Lardy [45], respectively. Acetyl-CoA-carboxylase (ACC, EC 6.4.1.2) was assayed by the $\mathrm{H}^{14} \mathrm{CO}_{3}$-fixation method [46, 47], using $\mathrm{H}^{14} \mathrm{CO}_{3}$ (NEN, Life Science Product, Boston, USA, $49 \mathrm{mCi} \cdot \mathrm{mmol}^{-1}$ ). ME and G6PDH activities were expressed as $\mu \mathrm{mol}$ of NADPH produced per min per total liver and $\mathrm{mg}$ of protein. ACC activity was expressed as nmol bicarbonate incorporated per min per total liver and $\mathrm{mg}$ of protein.

\subsubsection{Statistical analyses}

The data were analysed using the Statview 4.5 program (Abacus Concept, Bekerley, USA). Statistical differences between the means were determined by ANOVA and the Fisher test and considered to be significant at $P<0.05$.

\section{RESULTS}

\subsection{Growth and body parameters}

While body weights were the same at the beginning of the experimentation, final body weights differed slightly but significantly between the 4 groups, being the lowest with the highest doses of ALA dietary intake (Tab. II). This did not result from parallel differences in food intake and body weight gain during the last week, which were the highest in the L10 group and the lowest in the L20 group. At the end of the experimental period, body weight gain was almost null, suggesting the end of the hamster growth.

The differences of final body weights were not followed by any differences in the total or relative weights of the liver and EAT. 
Table III. Plasma lipids $\left(\mathrm{g} \cdot \mathrm{L}^{-1}\right)$.

\begin{tabular}{lllll}
\hline & \multicolumn{1}{c}{ L1 } & \multicolumn{1}{c}{ L10 } & \multicolumn{1}{c}{ L20 } & \multicolumn{1}{c}{ L40 } \\
\hline TC & $1.62 \pm 0.02^{\mathrm{b}}$ & $1.86 \pm 0.06^{\mathrm{a}}$ & $1.91 \pm 0.06^{\mathrm{a}}$ & $1.81 \pm 0.09^{\mathrm{a}}$ \\
TG & $1.52 \pm 0.26^{\mathrm{a}}$ & $0.83 \pm 0.05^{\mathrm{b}}$ & $0.72 \pm 0.14^{\mathrm{b}}$ & $0.94 \pm 0.15^{\mathrm{b}}$ \\
PL & $2.80 \pm 0.05^{\mathrm{a}}$ & $2.51 \pm 0.07^{\mathrm{b}}$ & $2.32 \pm 0.05^{\mathrm{c}}$ & $2.21 \pm 0.07^{\mathrm{c}}$ \\
HDL-TC & $1.38 \pm 0.13$ & $1.30 \pm 0.07$ & $1.23 \pm 0.12$ & $1.16 \pm 0.11$ \\
HDL-PL & $1.81 \pm 0.05^{\mathrm{ab}}$ & $1.97 \pm 0.06^{\mathrm{a}}$ & $1.73 \pm 0.11^{\mathrm{b}}$ & $1.62 \pm 0.06^{\mathrm{b}}$ \\
Non HDL-TC/HDL-TC & $0.39 \pm 0.06$ & $0.44 \pm 0.03$ & $0.61 \pm 0.12$ & $0.60 \pm 0.12$ \\
\hline
\end{tabular}

The results are mean \pm SEM of 6 hamsters in each group. The values with different superscripts are considered significantly different at $P<0.05$. The L1, L10, L20 and L40 diets contained respectively 1,10 , 20 and $41 \%$ (total fatty acids) of ALA or $0.4,3.6,6.7$ and $14.6 \%$ of total energy intake. TC: total cholesterol; TG: triglycerides; PL: phospholipids.

Table IV. Liver and bile composition.

\begin{tabular}{llcllll}
\hline & \multicolumn{1}{c}{ Unit } & \multicolumn{1}{c}{ L1 } & \multicolumn{1}{c}{ L10 } & \multicolumn{1}{c}{ L20 } & L40 \\
\hline Liver & TC & mg. - $^{-1}$ liver & $40.1 \pm 1.9^{\mathrm{a}}$ & $41.0 \pm 4.7^{\mathrm{a}}$ & $39.9 \pm 4.1^{\mathrm{a}}$ & $22.3 \pm 1.7^{\mathrm{b}}$ \\
& FC & - & $3.27 \pm 0.19^{\mathrm{a}}$ & $3.81 \pm 0.39^{\mathrm{a}}$ & $3.45 \pm 0.25^{\mathrm{a}}$ & $2.41 \pm 0.08^{\mathrm{b}}$ \\
& CE & - & $61.6 \pm 2.8^{\mathrm{a}}$ & $62.1 \pm 7.3^{\mathrm{a}}$ & $60.8 \pm 6.5^{\mathrm{a}}$ & $33.3 \pm 2.7^{\mathrm{b}}$ \\
& TG & - & $8.34 \pm 0.64^{\mathrm{ab}}$ & $9.50 \pm 0.50^{\mathrm{a}}$ & $7.67 \pm 0.51^{\mathrm{b}}$ & $8.56 \pm 0.47^{\mathrm{ab}}$ \\
& PL & - & $18.2 \pm 0.4^{\mathrm{a}}$ & $18.0 \pm 0.6^{\mathrm{ab}}$ & $15.6 \pm 2.1^{\mathrm{b}}$ & $9.0 \pm 0.3^{\mathrm{c}}$ \\
& PR & - & $184 \pm 11^{\mathrm{a}}$ & $190 \pm 4^{\mathrm{a}}$ & $183 \pm 4^{\mathrm{a}}$ & $194 \pm 3^{\mathrm{a}}$ \\
\hline Bile & TC & $\mathrm{g} \cdot \mathrm{L}^{-1}$ & $0.60 \pm 0.08^{\mathrm{b}}$ & $0.76 \pm 0.05^{\mathrm{ab}}$ & $0.96 \pm 0.07^{\mathrm{a}}$ & $0.79 \pm 0.16^{\mathrm{ab}}$ \\
& PL & - & $21.7 \pm 1.3^{\mathrm{b}}$ & $22.5 \pm 0.7^{\mathrm{b}}$ & $25.8 \pm 0.4^{\mathrm{a}}$ & $25.2 \pm 0.9^{\mathrm{a}}$ \\
& BA & - & $96.4 \pm 9.9$ & $93.8 \pm 6.3$ & $93.5 \pm 13.6$ & $95.3 \pm 6.4$ \\
\cline { 2 - 6 } & LI & & $0.08 \pm 0.01^{\mathrm{b}}$ & $0.10 \pm 0.01^{\mathrm{ab}}$ & $0.13 \pm 0.1^{\mathrm{a}}$ & $0.10 \pm 0.02^{\mathrm{ab}}$ \\
\hline
\end{tabular}

The results are mean \pm SEM of 6 hamsters in each group. The values with different superscripts are considered significantly different $(P<0.05)$. The L1, L10, L20 and L40 diets contained respectively 1,10 , 20 and $41 \%$ (total fatty acids) of ALA or $0.4,3.6,6.7$ and $14.6 \%$ of total energy intake. TC: total cholesterol; FC: free cholesterol; CE: cholesteryl esters; TG: triglycerides; PL: phospholipids; BA: bile acids; LI: lithogenic index. PR: proteins.

\subsection{Lipid composition of plasma, liver, and bile}

In the plasma, all groups fed the diets containing ALA (L10-L40), exhibited higher TC concentration than those fed the diet low in ALA (L1) but their TG concentrations was twice lower (Tab. III). These effects did not seem to be dependent on the ALA dose, on the contrary to the PL concentration, which decreased proportionally to the increase in dietary ALA. HDL-TC was the same in the 4 groups, whereas HDL-PL was higher in the animals fed the L10 diet than in those fed the L20 and L40 diets. The ratio (non HDL-TC)/(HDL-TC), that is an index of atherogenicity, did not vary among the 4 groups despite a slight and not significant increase in response to the higher ALA intakes (L20 and L40).

In the liver, the concentration of TC was nearly twice lower in hamsters fed the L40 diet, which was the richest in ALA, than in the other groups (Tab. IV). This was also observed for FC as well as CE, which was the main lipid in the liver. PL concentration was also the lowest in the hamsters fed the L40 diet. That of TG varied significantly among groups, but independently of dietary 


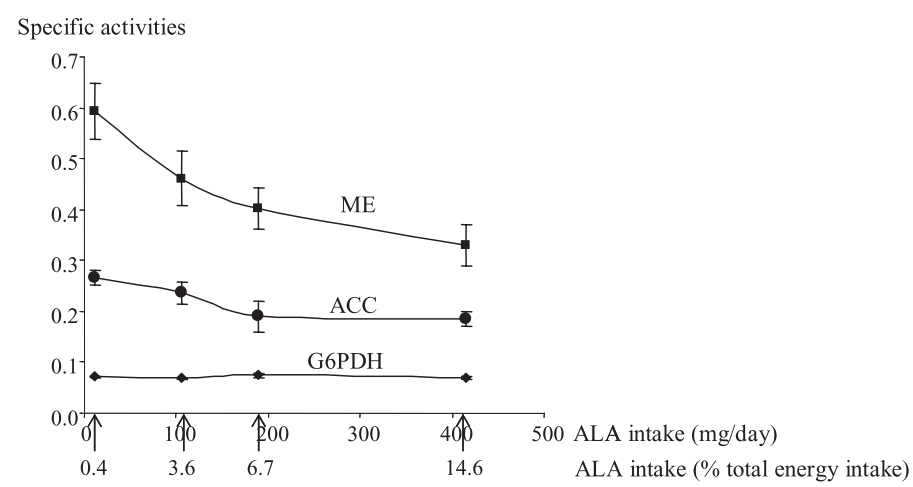

Figure 1. Specific activities of hepatic lipogenic enzymes as a function of dietary ALA intake. ME and G6PDH activities are expressed as $\mu$ mol NADPH produced per minute and per mg protein. ACC activity is expressed as nmol $\mathrm{HCO}^{-}$produced per minute and per $\mathrm{mg}$ protein. The results are mean \pm SEM of 6 hamsters per group. L1, L10, L20 and L40 diets contained respectively 1, 10, 20 and $41 \%$ (total fatty acids) of ALA or $0.4,3.6,6.7$ and $14.6 \%$ of total energy intake. ACC: acetylCoA carboxylase, G6PDH: glucose-6-phosphate dehydrogenase, ME: malic enzyme.

ALA intake. Indeed, it was the highest in hamsters fed the L10 diet, the lowest in those fed the L20 diet, and intermediary in response to the L1 and L40 diets. Expressed as the total quantity per liver, and whatever the lipids, the differences between the groups were the same as in concentrations (data not shown).

In bile, the concentration of BA, which were the main sterols, was identical in all groups. That of PL was higher with the L20 and L40 diets than with the two other diets, while that of cholesterol was higher in the animals fed the L20 diet than in those fed the $\mathrm{L} 1$ diet. In consequence, the animals fed the L20 diet exhibited a higher lithogenic index than those fed the L1 diet.

\subsection{Lipogenic enzyme activities}

In the liver, the specific activity of ACC decreased when the ALA intake increased, until it reached $6.7 \%$ of total energy intake (with the L20 diet) and then plateaued (Fig. 1). Similarly, the specific activity of ME, an NADPH supplier for FA synthesis, was inversely proportional to dietary ALA intake. However, and on the contrary to ACC, this decrease did not tend to a plateau.
By contrast, G6PDH, the other NADPH provider, was not affected by any dietary treatment; its activity was the same in all groups and at least 4 times lower than that of the ME. When expressed as the total enzymatic activity in the liver, the dose effect of dietary ALA did not differ markedly from that of specific activities (Tab. V). In addition, a significant correlation was found between triglyceridemia and the total activity of ACC and ME $\left(R^{2}=0.17, P=\right.$ 0.04 and $R^{2}=0.38, P=0.002$, respectively).

In the EAT, ACC and ME specific activities were at least 2 and 4-6 times lower than in the liver, respectively and were not affected by dietary ALA intake on the contrary to hepatic lipogenic enzymes (Tab. V). Surprisingly, G6PDH specific activity was 5 fold higher in EAT than in the liver, and was therefore the main NADPH supplier. As in the liver, neither specific nor total activities were affected by dietary ALA.

\subsection{Excretion of cholesterol and bile acids}

Faecal excretion of TC was $40 \%$ higher in animals fed the L40 diet than in those fed 
Table V. Activity of lipogenic enzymes in the liver and epididymal adipose tissue.

\begin{tabular}{lcccccc}
\hline & & Unit & L1 & L10 & L20 & L40 \\
\hline Liver & ACC & nmol HCO3-/min/liver & $163 \pm 9^{\mathrm{a}}$ & $146 \pm 12^{\mathrm{ab}}$ & $117 \pm 16^{\mathrm{b}}$ & $116 \pm 12^{\mathrm{b}}$ \\
& $\mathrm{ME}$ & $\mu \mathrm{mol} \mathrm{NADPH} / \mathrm{min} /$ liver & $365 \pm 39^{\mathrm{a}}$ & $286 \pm 33^{\mathrm{ab}}$ & $247 \pm 14^{\mathrm{b}}$ & $212 \pm 37^{\mathrm{b}}$ \\
& $\mathrm{G} 6 \mathrm{PDH}$ & $\mu \mathrm{mol} \mathrm{NADPH} / \mathrm{min} / \mathrm{liver}$ & $43.4 \pm 1.5$ & $42.4 \pm 1.1$ & $45.8 \pm 1.3$ & $43.1 \pm 1.8$ \\
\hline \multirow{2}{*}{ EAT } & ACC & nmol HCO3-/min/mg PR & $0.10 \pm 0.02$ & $0.06 \pm 0.01$ & $0.07 \pm 0.04$ & $0.07 \pm 0.01$ \\
& ME & $\mu \mathrm{mol} \mathrm{NADPH} / \mathrm{min} / \mathrm{mg}$ PR & $0.11 \pm 0.01$ & $0.11 \pm 0.02$ & $0.12 \pm 0.06$ & $0.12 \pm 0.02$ \\
& G6PDH & $\mu \mathrm{mol} \mathrm{NADPH} / \mathrm{min} / \mathrm{mg}$ PR & $0.54 \pm 0.08$ & $0.48 \pm 0.04$ & $0.48 \pm 0.07$ & $0.44 \pm 0.03$ \\
\hline
\end{tabular}

The results are mean \pm SEM of 6 hamsters in each group. The values with different superscripts are considered significantly different at $P<0.05$. ACC: Acetyl-CoA carboxylase; EAT. epididymal adipose; G6PDH : glucose-6-phosphate dehydrogenase; ME: malic enzyme. The L1, L10, L20 and L40 diets contained respectively 1, 10, 20 and $41 \%$ (total fatty acids) of ALA or $0.4,3.6,6.7$ and $14.6 \%$ of total energy intake.

Table VI. Daily excretion of faecal sterols and composition of faecal bile acids.

\begin{tabular}{lccccc}
\hline & Unit & L1 & L10 & L20 & L40 \\
\hline TC & mg.day $^{-1}$ & $1.25 \pm 0.04^{\mathrm{b}}$ & $1.26 \pm 0.07^{\mathrm{b}}$ & $1.12 \pm 0.07^{\mathrm{b}}$ & $1.53 \pm 0.06^{\mathrm{a}}$ \\
& $\mu{\text { mol } \cdot \mathrm{day}^{-1}}$ & $3.24 \pm 0.10^{\mathrm{b}}$ & $3.26 \pm 0.18^{\mathrm{b}}$ & $2.90 \pm 0.19^{\mathrm{b}}$ & $3.97 \pm 0.35^{\mathrm{a}}$ \\
BA excreted & $\mathrm{mg} \cdot$ day $^{-1}$ & $1.51 \pm 0.14^{\mathrm{a}}$ & $1.21 \pm 0.16^{\mathrm{a}}$ & $1.20 \pm 0.11^{\mathrm{a}}$ & $0.50 \pm 0.04^{\mathrm{b}}$ \\
& $\mu \mathrm{mol} \cdot \mathrm{day}^{-1}$ & $3.09 \pm 0.28^{\mathrm{a}}$ & $2.46 \pm 0.32^{\mathrm{a}}$ & $2.45 \pm 0.23^{\mathrm{a}}$ & $1.00 \pm 0.08^{\mathrm{b}}$ \\
Total sterols excreted & $\mu \mathrm{mol} \cdot \mathrm{day}^{-1}$ & $6.32 \pm 0.37^{\mathrm{a}}$ & $5.72 \pm 0.40^{\mathrm{ab}}$ & $5.35 \pm 0.40^{\mathrm{ab}}$ & $4.97 \pm 0.15^{\mathrm{b}}$ \\
Primary BA & $\%$ & $3.59 \pm 0.46^{\mathrm{b}}$ & $4.62 \pm 0.45^{\mathrm{b}}$ & $3.62 \pm 0.71^{\mathrm{b}}$ & $10.66 \pm 1.19^{\mathrm{a}}$ \\
Secondary BA/primary BA & & $30.0 \pm 4.3^{\mathrm{a}}$ & $22.0 \pm 2.7^{\mathrm{a}}$ & $31.3 \pm 5.1^{\mathrm{a}}$ & $8.9 \pm 1.0^{\mathrm{b}}$ \\
CA pathway & $\%$ & $56.4 \pm 0.6^{\mathrm{a}}$ & $54.1 \pm 2.3^{\mathrm{a}}$ & $55.6 \pm 1.4^{\mathrm{a}}$ & $44.9 \pm 1.8^{\mathrm{b}}$ \\
CA pathway/ CDCA pathway & & $1.30 \pm 0.04^{\mathrm{a}}$ & $1.21 \pm 0.10^{\mathrm{a}}$ & $1.26 \pm 0.07^{\mathrm{a}}$ & $0.83 \pm 0.06^{\mathrm{b}}$ \\
\hline
\end{tabular}

The results are mean \pm SEM of 6 hamsters in each group. The values with different superscripts are considered significantly different $(P<0.05)$. The L1, L10, L20 and L40 diets contained respectively 1, 10, 20 and $41 \%$ (total fatty acids) of ALA or $0.4,3.6,6.7$ and $14.6 \%$ of total energy intake. TC: cholesterol + derivatives; BA: bile acids; CA:cholic acid; CDCA:chenodesoxycholic acid; Primary BA: cholic acid + chenodesoxycholic acid; Cholic acid pathway $=$ cholic acid + lithocholic acid.

the other diets (Tab. VI). On the contrary, these animals exhibited a lower excretion of BA, which was decreased by at least $60 \%$ when compared to the three other groups. Not only the quantity but also the quality of faecal bile acids was affected by dietary treatment (Tab. VI). Indeed, in response to the L40 diet, primary bile acids increased at the expense of secondary bile acids, while the chenodesoxycholic acid pathway was favoured over the cholic acid pathway.

\section{DISCUSSION}

In the present study, we investigated the effects of increased doses of dietary ALA on lipid metabolism in a validated rodent model. We chose a broad range of ALA intake while keeping LA intake constant, which resulted in the LA/ALA ratio varying between 22.5 and 0.6. SFA intake was also similar in all the diets, so that we evaluated the specific effects of ALA and not the 
effects of a substitution of PUFA for SFA. Under the same nutritional conditions, ALA transport, storage and conversion into EPA was shown to be strictly proportional to dietary intake [30]. This linear relationship has to be taken into account in discussing the dose effect of dietary ALA on lipid metabolism.

\subsection{Triglyceride metabolism}

The substitution of ALA for oleic acid led to a $45 \%$ fall in triglyceridemia which appeared as soon as the ALA content in the diet reached $10 \%$ of total fatty acids $(3.6 \%$ total energy), and was not amplified by higher ALA supplies (Tab. III). Such a hypotriglyceridemic effect was also reported in the rat with a similar intake of ALA $(9.9 \%$ total fatty acids, $4.0 \%$ of total energy) [48].

This dramatic fall in plasma TG in response to dietary ALA is consistent with the decrease in the specific activity of two lipogenic enzymes, ME and ACC (Fig. 1 and Tab. V). Interestingly, in the liver, the down-regulation of NADPH supplier activity by ALA affected only the main supplier, $\mathrm{ME}$, and was not effective on G6PDH. Moreover, the correlation between triglyceridemia and the total activity per liver of ACC and ME supports our hypothesis that the fall in lipogenic enzyme activities could, at least partly, explain the decrease in plasma TG. The activity of fatty acid synthase (FAS), the other major lipogenic enzyme, could also contribute to hypotriglyceridemia, (i) since FAS was highly correlated to liver and serum TG in rats [19] and (ii) substitution of ALA for oleic acid decreased FAS activity in rats [49]. As with LC-PUFA, this decreased activity could originate from an inhibition of lipogenic gene expression by ALA, as described in cultured hepatocytes [20]. This was consistent with other studies on cultured hepatocytes, showing that VLDL-TG secretion was lower when ALA was present in the medium instead of oleic acid [50, 51]. How- ever, the dose-effect of dietary ALA on VLDL-TG secretion, as well as on the activity of FAS, remains to be investigated.

Besides, under the same nutritional conditions, both ALA and EPA were transported and stored proportionally to dietary ALA intake [30]. Therefore, it remains difficult to decide which fatty acid is the most potent inhibitor of lipogenesis in vivo.

The apparent discrepancy between the proportional decrease in ME and ACC and the decrease in triglyceridemia independently of the dose could be due to a doserelated channelling of newly synthesised FA between oxidation, in situ storage of TG, and secretion of VLDL. In our conditions, the balance between storage and secretion did not appear to be dose-dependent since, as in plasma, hepatic TG content did not vary in proportion to ALA intake (Tab. IV). Therefore, a lower proportion of TG stored in the liver cannot be responsible for the steady plasma concentration of TG in response to increased dietary ALA. Finally, we could also hypothesise that oxidation declined with higher doses of ALA, which would increase the pool of secreted TG and could prevent a further decrease in plasma TG concentration. This mechanism is very unlikely, since rats fed high doses of ALA (57\% total fatty acids, $15-20 \%$ total energy) exhibited higher mitochondrial and peroxisomal oxidation rates than those fed palm (rich in SFA and oleic acid) or safflower (rich in LA) oil [21]. Therefore, it is possible that, in these fasting animals, triglyceridemia did not parallel the inhibition of lipogenic activity, because the decrease in de novo fatty acid synthesis is compensated for by fatty acids originating from the adipose tissue and recycled by the liver in the form of TG.

In contrast with the liver, lipogenic activity in the EAT was not responsive to ALA intake (Tab. VI), which was consistent with the absence of variations in EAT weights among groups (Tab. II). 


\subsection{Sterol metabolism}

Cholesterol metabolism was also affected by the dietary treatment, since plasma TC slightly but significantly increased to the same extent $(15 \%)$ in response to the substitution of ALA for oleic acid (Tab. III). However, the two forms of cholesterol transport, apoB-containing lipoproteins (non HDL) and HDL were affected to a similar extent. Nevertheless, the trend to an increase in the atherogenic index (non-HDL-TC/HDL-TC) has to be considered carefully in further investigations. Hypercholesterolemia was due neither to a lower hepatic storage of CE, which was the same in the L1, L10 and L20 groups (Tab. IV), nor to a weaker faecal excretion of total sterols (TC $+\mathrm{BA})$, which was identical in these 3 groups (Tab. VI). The present study did not allow drawing a clear cut explanation for the hypercholesterolemic effect of dietary ALA, which may regulate other key points of sterol metabolism, such as cholesterol and BA synthesis $[52,53]$, or cholesterol uptake by the liver via lipoprotein receptors [54]. However, differences in the experimental models and/ or dietary conditions do not allow extrapolating to our study. The specific effects of ALA on cholesterol metabolism have to be investigated further in our experimental conditions.

On the contrary to other parameters that were sensitive to low ALA intake, hepatic TC content was dramatically diminished in response to the highest dose of ALA. This was parallel with a $28 \%$ higher TC faecal excretion and a $61 \%$ fall in BA excretion, which resulted in a slightly decreased faecal secretion of total sterols. Moreover, in hamsters fed the highest dose of ALA, the BA profile was markedly modified: the proportions between the cholic and the chenodeoxycholic acids pathways were switched, the former being clearly lower in the L40 group than in the three others. This switch increased the hydrophobicity of bile in the animals of the L40 group, and thus, their propensity to develop biliary stones [55]. Sterol 12-hydroxylase (CYP8B1) is the specific enzyme for cholic acid synthesis and determines the ratio of cholic to chenodeoxicholic acid. This enzyme is known to be upregulated by SREBP1 [56] of which the promoter is inhibited by ALA in rat hepatocytes [57]. These studies suggest that our decrease in the ratio of cholic to chenodeoxicholic acid may be due to an inhibition of sterol 12-hydroxylase via SREBP1. In addition, the 2-3-fold increase in the percentage of primary BA rise is indicative of a decline in the bacterial activity of BA transformation. Thus the L40 diet highly affected the BA metabolism in its synthesis as well as in its transformation in the colon.

\section{CONCLUSION}

In our hamster model, the proportions of SFA and LA were kept constant, so that dietary effects in lipid metabolism could not be accounted for by a decrease in SFA as is often the case in human studies. Under these conditions, the only variable was the oleic/ALA ratio, and a previous study showed that ALA transport, storage, and conversion into EPA were strictly proportional to dietary ALA intake (30). By contrast, in the present study, increasing dietary ALA did not result in a linear dose-response of all lipid parameters that were affected in different ways: (i) plasma TG and cholesterol responded to the lowest ALA supply (10\% FA, $3.6 \%$ total energy) and were not further affected by higher doses; (ii) the activity of lipogenic enzymes (ACC and ME) was negatively correlated to dietary ALA intake; (iii) liver TC, faecal excretion of TC and BA, and BA profiles varied only with very high ALA intakes.

In the human, plasma TG concentration was shown to increase [16], not change [1, 12], or decrease [17] in response to dietary ALA. In the present study, the hypotriglyceridemia was not affected by an increased ALA intake, (at least between 3.6 and $14.6 \%$ of total energy intake). Therefore, it is possible that the discrepancies between human studies on TG concentration may 
not be due to the dose of ALA used (1.8$12 \%$ of total energy intake) $[12,16,17]$. More probably, the diversity of fatty acids which were substituted for by ALA could explain these discrepancies. On sterol metabolism, however, the effects could be different depending on whether the ALA dose is moderate or very high.

Moreover, a moderate ALA intake (3.6\% total energy) was sufficient to decrease triglyceridemia that, in itself, is a risk factor of CVD, via a decline in lipogenesis. This dose was consistent with those used in human studies (1-6\% total energy intake). However under our conditions, this dose was also sufficient to slightly raise cholesterolemia, which needs further verifications. High doses of ALA emphasised neither the hypotriglyceridemic nor the hypercholesterolemic effects observed with low doses. In contrast, the very high and non physiological doses engendered adverse effects on BA metabolism.

\section{ACKNOWLEDMENTS}

The authors gratefully acknowledge the financial support work of ONIDOL and ONIOL. They also sincerely thank Guillaume Chesneau and the Valorex company (La Messayais, 35210 Combourtillé, France) for providing linseed oil, Gwennola Robin (SENAH) for her valuable contribution to the measurement of lipogenic enzyme activities, Bernadette Delplanque and Jacqueline Férézou (Université Paris-Sud) for their precious scientific advice, and Nathalie Samson (Université Paris-Sud) for animal care.

\section{REFERENCES}

[1] Simopoulos AP. N-3 fatty acids and human health: defining strategies for public policy. Lipids 2001, 36 (Suppl): S83-S89.

[2] Nordoy A, Marchioli R, Arnesen H, Videbaek J. N-3 polyunsaturated fatty acids and cardiovascular diseases. Lipids 2001, 36: S127S129.

[3] Renaud S, de Lorgeril M, Delaye J, Guidollet J, Jacquard F, Mamelle N, Martin JL, Monjaud I, Salen P, Toubol P. Cretan Mediterranean diet for prevention of coronary heart disease. Am J Clin Nutr 1995, 61: 1360S-1367S.

[4] De Lorgeril M, Renaud S, Mamelle N, Salen P, Martin JL, Monjaud I, Guidollet J, Touboul $\mathrm{P}$, Delaye J. Mediterranean alpha-linolenic acid-rich diet in secondary prevention of coronary heart disease. Lancet 1994, 343: 1454 1459.

[5] Combe N, Boué C. Apports alimentaires en acide linoléique et alpha-linolénique d'une population d'Aquitaine. OCL 2001, 8: 118121.

[6] Harel Z, Riggs S, Vaz R, White L, Menzies G. Omega-3 polyunsaturated fatty acids in adolescents: knowledge and consumption. J Adolesc Health 2001, 28: 10-15.

[7] Kris-Etherton PM, Taylor DS, Yu-Poth S, Huth P, Moriarty K, Fishell V, Hargrove RL, Zhao G, Etherton TD. Polyunsaturated fatty acids in the food chain in the United States. Am J Clin Nutr 2000, 71: 179S-188S.

[8] Sanderson P, Finnegan YE, Williams CM, Calder PC, Burdge GC, Wootton SA, Griffin BA, Joe Millward D, Pegge NC, Bemelmans WJ. UK Food Standards Agency alpha-linolenic acid workshop report. Br J Nutr 2002, 88: 573-579.

[9] Freese R, Mutanen M. Alpha-linolenic acid and marine long-chain n-3 fatty acids differ only slightly in their effects on hemostatic factors in healthy subjects. Am J Clin Nutr 1997, 66: 591-598.

[10] Bemelmans WJ, Muskiet FA, Feskens EJ, de Vries JH, Broer J, May JF, Jong BM. Associations of alpha-linolenic acid and linoleic acid with risk factors for coronary heart disease. Eur J Clin Nutr 2000, 54: 865-871.

[11] Harris WS. N-3 fatty acids and serum lipoproteins: animal studies. Am J Clin Nutr 1997, 65 : 1611S-1616S.

[12] Nydahl M, Gustafsson IB, Ohrvall M, Vessby B. Similar serum lipoprotein cholesterol concentrations in healthy subjects on diets enriched with rapeseed and with sunflower oil. Eur J Clin Nutr 1994, 48: 128-137.

[13] Karvonen HM, Aro A, Tapola NS, Salminen I, Uusitupa MI, Sarkkinen ES. Effect of alphalinolenic acid-rich Camelina sativa oil on serum fatty acid composition and serum lipids in hypercholesterolemic subjects. Metabolism 2002, 51: 1253-1260.

[14] Pang D, Allman-Farinelli MA, Wong T, Barnes R, Kingham KM. Replacement of linoleic acid with alpha-linolenic acid does 
not alter blood lipids in normolipidaemic men. Br J Nutr 1998, 80: 163-167.

[15] Mantzioris E, James MJ, Gibson RA, Cleland LG. Dietary substitution with an alpha-linolenic acid-rich vegetable oil increases eicosapentaenoic acid concentrations in tissues. Am J Clin Nutr 1994, 59: 1304-1309.

[16] Bemelmans WJ, Broer J, Feskens EJ, Smit AJ, Muskiet FA, Lefrandt JD, Bom VJ, May JF, Meyboom-de Jong B. Effect of an increased intake of alpha-linolenic acid and group nutritional education on cardiovascular risk factors: the Mediterranean Alpha-linolenic Enriched Groningen Dietary Intervention (MARGARIN) study. Am J Clin Nutr 2002, 75: 221-227.

[17] Singer P, Jaeger W, Berger I, Barleben H, Wirth M, Richter-Heinrich E, Voigt S, Godicke W. Effects of dietary oleic, linoleic and alphalinolenic acids on blood pressure, serum lipids, lipoproteins and the formation of eicosanoid precursors in patients with mild essential hypertension. J Hum Hypertens 1990, 4: 227 233.

[18] Djousse L, Hunt SC, Arnett DK, Province MA, Eckfeldt JH, Ellison RC. Dietary linolenic acid is inversely associated with plasma triacylglycerol: the National Heart, Lung, and Blood Institute Family Heart Study. Am J Clin Nutr 2003, 78: 1098-1102.

[19] Ikeda I, Cha JY, Yanagita T, Nakatani N, Oogami K, Imaizumi K, Yazawa K. Effects of dietary alpha-linolenic, eicosapentaenoic and docosahexaenoic acids on hepatic lipogenesis and beta-oxidation in rats. Biosci Biotechnol Biochem 1998, 62: 675-680.

[20] Jump DB, Clarke SD, Thelen A, Liimatta M. Coordinate regulation of glycolytic and lipogenic gene expression by polyunsaturated fatty acids. J Lipid Res 1994, 35: 1076-1084.

[21] Ide T, Kobayashi H, Ashakumary L, Rouyer IA, Takahashi Y, Aoyama T, Hashimoto T, Mizugaki M. Comparative effects of perilla and fish oils on the activity and gene expression of fatty acid oxidation enzymes in rat liver. Biochim Biophys Acta 2000, 1485: 23-35.

[22] Finnegan YE, Minihane AM, Leigh-Firbank EC, Kew S, Meijer GW, Muggli R, Calder PC, Williams CM. Plant- and marine-derived n-3 polyunsaturated fatty acids have differential effects on fasting and postprandial blood lipid concentrations and on the susceptibility of LDL to oxidative modification in moderately hyperlipidemic subjects. Am J Clin Nutr 2003, 77: 783-795.
[23] Li D, Sinclair A, Wilson A, Nakkote S, Kelly F, Abedin L, Mann N, Turner A. Effect of dietary alpha-linolenic acid on thrombotic risk factors in vegetarian men. Am J Clin Nutr 1999, 69: 872-882.

[24] Mohrhauer H, Holman RT. The effect of dose level of essential fatty acids upon fatty acid composition of the rat liver. J Lipid Res 1963, 58: 151-159.

[25] Pudelkewicz C, Seufert J, Holman RT. Requirements of the female rat for linoleic and linolenic acids. J Nutr 1968, 94: 138-146.

[26] Kabir Y, Ide T. Activity of hepatic fatty acid oxidation enzymes in rats fed alpha-linolenic acid. Biochim Biophys Acta 1996, 1304: 105119.

[27] Surette ME, Whelan J, Lu GP, Broughton KS, Kinsella JE. Dependence on dietary cholesterol for $n-3$ polyunsaturated fatty acid-induced changes in plasma cholesterol in the Syrian hamster. J Lipid Res 1992, 33: 263-271.

[28] Spady DK, Kearney DM, Hobbs HH. Polyunsaturated fatty acids up-regulate hepatic scavenger receptor B1 (SR-BI) expression and HDL cholesteryl ester uptake in the hamster. J Lipid Res 1999, 40: 1384-1394.

[29] Goulinet S, Chapman MJ. Plasma lipoproteins in the golden Syrian hamster (Mesocricetus auratus): heterogeneity of apoB- and apoA-I-containing particles. J Lipid Res 1993, 34: 943-959.

[30] Morise A, Combe N, Boué C, Legrand P, Catheline D, Delplanque B, Fénart E, Weill P, Hermier D. Dose effect of alpha-linolenic acid on PUFA conversion, bioavailability and storage in the hamster. Lipids 2004, 39: 325-334.

[31] Folch J, Lees M, Sloane-Stanley GH. A simple method for the isolation and purification of total lipids from animal tissues. J Biol Biochem 1957, 226: 497-509.

[32] Morisson W, Smith L. Preparation of fatty acid methyl esters and dimetylacetals from lipids with boron fluoride methanol. J Lipid Res 1964, 5: 600-608.

[33] Boehler N, Riottot M, Ferezou J, Souidi M, Milliat F, Serougne C, Smith JL, Lutton C. Antilithiasic effect of beta-cyclodextrin in LPN hamster: comparison with cholestyramine. J Lipid Res 1999, 40: 726-734.

[34] Richmond W. Preparation and properties of a cholesterol oxidase from Nocardia sp. and its application to the enzymatic assay of total cholesterol in serum. Clin Chem 1973, 19: 1350-1356. 
[35] Takayama M, Itoh S, Nagasaki T, Tanimizu I. A new enzymatic method for determination of serum choline-containing phospholipids. Clin Chim Acta 1977, 79: 93-98.

[36] Fossati P, Prencipe L. Serum triglycerides determined colorimetrically with an enzyme that produces hydrogen peroxide. Clin Chem 1982, 28: 2077-2080.

[37] Burstein M, Scholnick HR, Morfin R. Rapid method for the isolation of lipoproteins from human serum by precipitation with polyanions. J Lipid Res 1970, 11: 583-595.

[38] Turley SD, Dietschy JM. Re-evaluation of the 3 alpha-hydroxysteroid dehydrogenase assay for total bile acids in bile. J Lipid Res 1978 , 19: 924-928.

[39] Thomas PJ, Hofmann AF. Letter: A simple calculation of the lithogenic index of bile: expressing biliary lipid composition on rectangular coordinates. Gastroenterology 1973, 65: 698-700.

[40] Loison C, Mendy F, Serougne C, Lutton C. Dietary myristic acid modifies the HDL-cholesterol concentration and liver scavenger receptor BI expression in the hamster. $\mathrm{Br} \mathrm{J}$ Nutr 2002, 87: 199-210.

[41] Lowry OH, Rosebrough NJ, Farr AL, Randal RJ. Protein measurement with the Folin phenol reagent. J Biol Chem 1951, 193: 265-275.

[42] Mourot J, Guy G, Lagarrigue S, Peiniau P, Hermier D. Role of hepatic lipogenesis in the susceptibility to fatty liver in the goose (Anser anser). Comp Biochem Physiol B Biochem Mol Biol 2000, 126: 81-87.

[43] Gandemer G, Pascal G, Durand G. Lipogenic capacity and relative contribution of the different tissues and organs to lipid synthesis in male rat. Reprod Nutr Dev 1983, 23: 575-586.

[44] Fitch WM, Hill R, Chaikoff IL. The effect of fructose feeding on glycolytic enzyme activities of the normal rat liver. J Biol Chem 1959, 234: 1048-1051.

[45] Hsu RY, Lardy HA. Malic enzyme. In: Lowenstein JM (Ed), Methods in Enzymology, New-York, 1969, p 230-235.

[46] Chakrabarty K, Leveille GA. Acetyl CoA carboxylase and fatty acid synthetase activities in liver and adipose tissue of meal-fed rats. Proc Soc Exp Biol Med 1969, 131: 1051-1054.

[47] Chang HC, Seidman I, Teebor G, Lane MD. Liver acetyl CoA carboxylase and fatty acid synthetase: relative activities in the normal state and in hereditary obesity. Biochem Biophys Res Commun 1967, 28: 682-686.
[48] Baba NH, Antoniades K, Habbal Z. Effects of dietary canola, olive and linolenic acid enriched olive oils on plasma lipids, lipid peroxidation and lipoprotein lipase activity in rats. Nutr Res 1999, 19: 601-612.

[49] Musch K, Ojakian MA, Williams MA. Comparison of alpha-linolenate and oleate in lowering activity of lipogenic enzymes in rat liver: evidence for a greater effect of dietary linoleinate independent of food and carbohydrate intake. Biochim Biophys Acta 1974, 337: 343-348.

[50] Fujiwama-Fujiwara Y, Igarashi O. Effect of oleic, linoleic, [gamma]-linolenic, and [alpha]linolenic acids on VLDL-TG and -cholesterol synthesis in rat primary cultured hepatocytes. Pathophysiology 1994, 1: 143-149.

[51] Dokko RC, Cho BH, Chung BH. Cellular uptake of stearic, oleic, linoleic, and linolenic acid and their effects on synthesis and secretion of lipids in Hep-G2 cells. Int J Biochem Cell Biol 1998, 30: 65-76.

[52] Ihara-Watanabe M, Umekawa H, Takahashi T, Furuichi Y. Comparative effects of safflower oil and perilla oil on serum and hepatic lipid levels, fatty acid compositions of serum and hepatic phospholipids, and hepatic mRNA expressions of 3-hydroxy-3-methylglutaryl CoA reductase, LDL receptor, and cholesterol 7 alpha-hydroxylase in young and adult rats. Food Res Int 2000, 33: 893-900.

[53] Morise A, Sérougne C, Gripois D, Blouquit MF, Lutton C, Hermier D. Effects of dietary alpha linolenic acid on cholesterol metabolism in male and female hamsters of the LPN strain. J Nutr Biochem 2004, 15: 51-61.

[54] Bucci C, Seru R, Annella T, Vitelli R, Lattero D, Bifulco M, Mondola P, Santillo M. Free fatty acids modulate LDL receptor activity in BHK-21 cells. Atherosclerosis 1998, 137: 329-340.

[55] Shaw R, Elliott WH. Competitive inhibitors of rabbit hepatic microsomal 12 alpha-steroid hydroxylase. J Biol Chem 1979, 254: 7177 7182

[56] Del Castillo-Olivares A, Gil G. Differential effects of sterol regulatory binding proteins 1 and 2 on sterol 12 alpha-hydroxylase. SREBP-2 suppresses the sterol 12 alpha-hydroxylase promoter. J Biol Chem 2002, 277: 6750-6757.

[57] Deng X, Cagen LM, Wilcox HG, Park EA, Raghow R, Elam MB. Regulation of the rat SREBP-1c promoter in primary rat hepatocytes. Biochem Biophys Res Commun 2002, 290: 256-262. 